\title{
The proclivity of free-ranging indigenous village chickens for night-time roosting in trees
}

\author{
Takele Taye Desta* ${ }^{*}$
}

\begin{abstract}
Background: Roosting in trees exhibits the instinct and widespread practice of the night enclosure system in indigenous village chickens (IVCs) of the tropics. This work reviews the predisposition of IVCs for night-time roosting in trees and summarizes the pros and cons of this natural behavior. It is largely focused on personal insights which were then refined further by informal discussions. Besides, literature was consulted to recapitulate the accidental observational study.

Main topics: Night-time roosting in trees although in most instances is performed by a small proportion of farmers, is a widely practiced night enclosure system in the tropics. Roosting in trees eliminates the labor and the cost needed to construct night enclosures. It reduces contact with soiled bedding materials and droppings, parasites, and pathogens, consequently, it improves the health status and welfare of the family flock. It enables IVCs to express their inbuilt behavior and to evade predators. It carries the legacy of the ancient chicken rearing system and it is eco-friendly practice. However, in the absence of protective structures such as fences, it exposes IVCs to nocturnal predators and theft. However, this can be circumvented using guarding dogs. Birds might be also affected by adverse weather, although they are thought to be resilient to such environmental changes.
\end{abstract}

Conclusions: The sustainability, economic feasibility, and welfare of IVCs roosting in a tree need to be assessed to make it a justifiable practice. This piece of work likely elicits research questions to conduct an in-depth study on the existing systems of using trees as night-time roosting sites for IVCs.

Keywords: Roosting in trees, Indigenous village chickens, Inbuilt behavior, Comparative advantage, The tropics

\section{Background}

Indigenous village chickens (IVCs) display an array of morphological characteristics and their genetic structure is mainly shaped by natural selection. Mating is virtually uncontrolled and scavenging (free-ranging) is the major source of feed. IVCs share most of the behavioral and morphological characteristics of junglefowl (Desta 2019; Bibi et al. 2021). IVCs are kept by subsistence farmers and are managed under an extensive system. IVCs are general-purpose chickens, accordingly, they provide several products and services such as egg, meat, and feather

\footnotetext{
*Correspondence: takele_taye@yahoo.com
}

Department of Biology, College of Natural and Computational Science,

Kotebe Metropolitan University, Addis Ababa, Ethiopia production, brooding and hatching, leisure (cockfighting), ecological (e.g., insect and pest, and weed control, seed dispersal, and environmental cleaning), and ritual services (Desta 2021). IVCs are the most common types of chicken in the less developed world. Night enclosure of IVCs is basic and is constructed using locally available resources.

Chickens prefer to roost on elevated structures to enhance their survivability. Night-time roosting in trees demonstrates the propensity of chickens to sleep in a safe place out of the reach of ground-dwelling nocturnal predators. Although not arboreal, or at least not regular tree-dwellers (Leahy 1982) it has been found that some of the indigenous village chickens (IVCs) in subsistence farming systems of the less developed world are roosting 
in trees during the night-time (e.g., Asem-Bansah et al. 2012; FAO 2013) and this practice has been noticed even in cities backyard chicken production system (Fig. 1). In the United States of America, free-ranging chickens used to roost in trees (Moore n.d.; Dryden 1910). Roosting in trees is an instinct behavior of both chickens and their living wild relatives - the junglefowl (Collias and Collias 1967; Desta 2019). However, there is a subtle spatial difference in the proportion of IVC flocks roosting in trees. For example, it has been practiced by $1 \%$ of Myanmar's (Henning et al. 2007); 8\% of Nigerian (El-Yuguda et al. 2007), 1.6\% of Indian (Vijh et al. 2006), and 5\% of Ethiopian farmers (Getu and Birhan 2014). However, in some instances, it is a common practice, for example, $65.13 \%$ of the rural households roost their chickens overnight in trees in Keana, Nasarawa state, Nigeria (Hassan et al. 2012) and $43.3 \%$ in the Gulu region of Uganda, conversely, none of the IVCs were roosting in trees in the Kiryandongo region (Aline 2015). This variation in the practice of using trees as night-time roosting sites may have aroused from disparities in predators' pressure and environmental temperature. Accordingly, when predators' pressure is less and thermal temperature is high, the likelihood of roosting in trees could be high.

Regardless of decades of post-domestication breeding and management history, IVCs have faithfully maintained the instinct of their living wild ancestors. Roosting in trees enables the IVCs to express their in-built protective behaviors and survival instincts. Roosting in a tree is sometimes accompanied by bush nesting (hiding)
(NSPD 2007). Sleeping in trees associates with the freeranging behavior of IVCs and acknowledges pecking order. Therefore, whenever the roosting space is limited and potential danger is felt, the alpha chicken (perhaps a free-living hen) roosts high on the safest branch of a tree (Olsson and Keeling 2000). The pros and cons of roosting in trees at night are discussed in the following sections.

\section{Methods used to collate facts}

The author was highly intrigued when encountered with IVCs that have been slept in a tree at night for about 5 years while visiting relatives in Adama (a.k.a. Nazareth) city that is located in central south-east Ethiopia. This intriguing observation has triggered the write-up of this piece of work. This has been followed by hot conversations and informal discussions to gain insight into the feasibility of this night enclosure system. The literature was consulted to support the insights gained from an accidental observations and informal discussions. This work reviews the predisposition of IVCs for night-time roosting in trees and summarizes the pros and cons of this instinctive behavior.

\section{The pros and cons of roosting in trees}

Night-time roosting in trees is evolutionarily conserved in the majority of the avian species. It might have been however subjected to differential selection pressure (Olsson and Keeling 2000). This shows that it confers an adaptive advantage to avian lineages and enhances their survivability, therefore, its advantages may excel

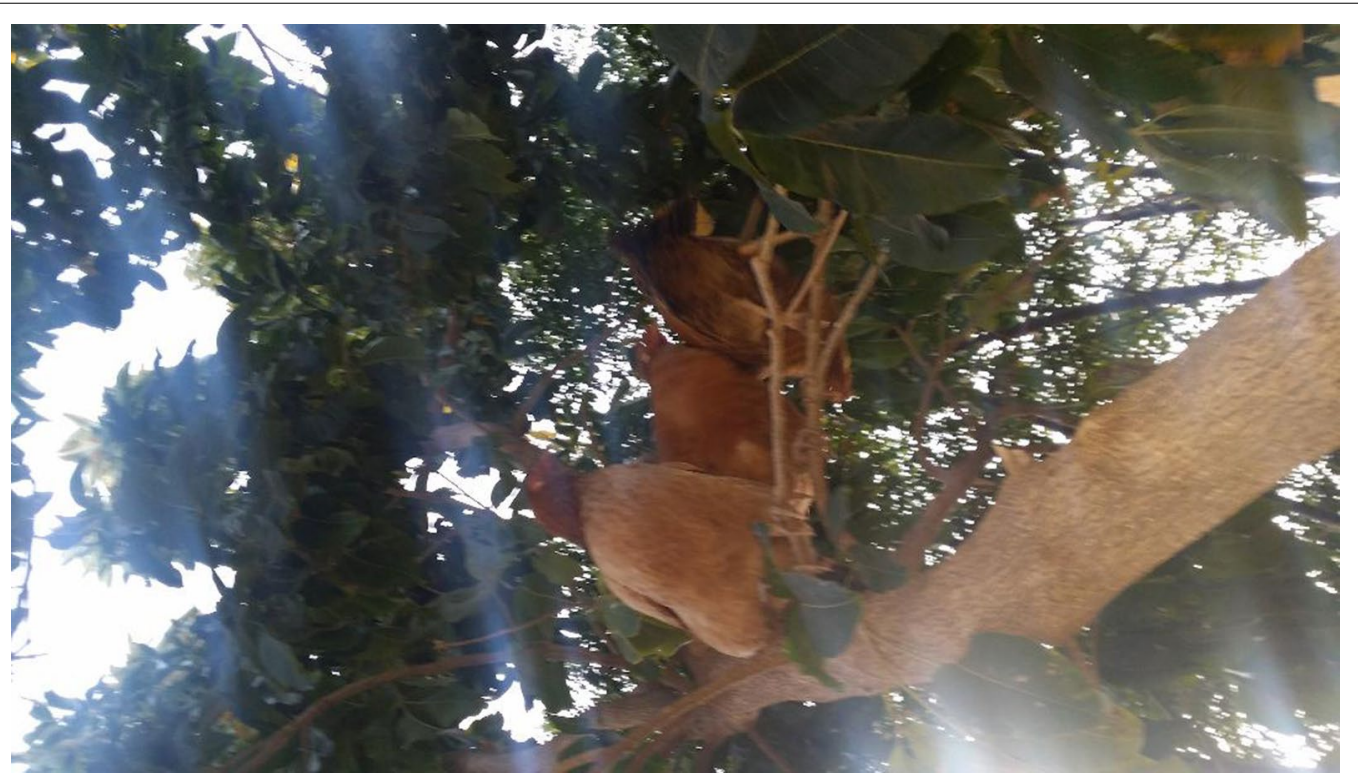

Fig. 1 Backyard indigenous village chickens roosting in a tree at night-time in Adama (a.k.a. Nazareth) city (https://en.wikipedia.org/wiki/Adama\#/ media/File:AdamaHotels.jpg), central south-eastern Ethiopia (courtesy of the Author) 
the associated limitations. This trait is observed not only in the wild birds but also in the domestic (to a varying extent) and feral populations (Wood-Gush and Duncan 1976; Desta 2019) therefore, domestication and the associated anthropogenic effects have not managed to eliminate the expression of this trait in domestic fowl and sibling poultry species. Even commercial chickens show a preference for perching which shows its adaptive advantage (Olsson and Keeling 2000).

\section{The health benefit of roosting in trees}

Roosting in trees is advantageous in that it reduces the spread of diseases (Spradbrow 2001; Asem-Bansah et al. 2012) by enhancing the free movement of air, and by reducing soiling, overcrowding, and physical contact (Huchzermeyer 1993). Moreover, sick birds that have lost their physical strength to roost in a tree, incubating and brooding hens along with their chicks remained separated from the rest of the group, therefore, the segregation of flock reduces the spread of diseases (Huchzermeyer 1993) and even the risk of mass killing provoked by predators. Ventilation suppresses the multiplication and growth of ectoparasites such as mites and lice and pathogens (Hinkle and Corrigan 2020). Keeping the chickens away from the litter materials and dirty floors improves their health status (Ahlers et al. 2009). When IVCs are kept inside night enclosures, they might be crowded-a recipe for an accelerated spread of disease, whereas roosting in trees enables them to spread apart and relax. By roosting in trees, the risk of spreading zoonotic diseases, ectoparasites, and the diffusion of bad odor to the household could be minimized.

\section{Roosting in trees boosts predators evading ability}

Tight confinement may limit IVCs predator evading ability especially when the night enclosure is poorly maintained (Dryden 1910). However, chickens usually roost communally to maintain balance, feel warm, and scare off predators. IVCs protect themselves from daytime aerial predators when they roost or are flocked under the canopy of a tree. Trees also serve as live shelters against wind, rain, and sunburn (NSPD 2007). Therefore, roosting trees provide both sheltering (at day-times) and roosting (at night-times) functions. However, IVCs might be not well protected from nocturnal predators (Morêki 2003; FAO 2013; Aline 2015) especially by that can climb a tree and conceal within the branches of a tree and theft as they are left loose and unsecured. Providing at least one extra tree within the flying range of IVCs may enhance the chance of escaping predators by jumping between trees as has been noticed in capercaillie Tetrao urogallus (Thiel et al. 2007). Regardless of this, roosting in trees enhances predators (Asem-Bansah et al. 2012) and theft spotting and evading ability as it keeps the flock at an elevated strategic position. For example, whilst tree-climbing predators approaching communally roosted chickens, the vibration of tree branches warns them (Leahy 1982) and they can float and run away. Moreover, when predators and thieves appear, IVCs like sibling birds may possess high sighting and tactile capacity (Leahy 1982) which makes them cackle and warn their owners to drive away predators and thieves. Predators and thieves, however, can be controlled using guarding dogs and/or fences. In Nicaragua, the roosting tree is covered by a piece of the sink to evade predators (de Vries 2000). The IVCs should have to roost concealed in tree branches or the roosting site should have to enable them to quickly escape the moment they are spotted by predators. However, the roosting trees need to have open surroundings to locate visiting predators and interestingly predators scared of trespassing open spaces.

\section{Roosting in trees enhances the welfare of the family flock}

Roosting in a tree keeps the chickens off the ground, and enables them to gain confidence (Ahlers et al. 2009), and reduces the annoyance of insects such as ants and termites. The proximity of IVCs to trees enables them to get access to plenty of oxygen. The quality of air improves as the IVCs stay off the ground. The oxygen that is produced by trees may be to some extent neutralize the bad odor of the droppings and litter materials. Drinking water is usually kept under trees which enables the IVCs to drink cold water. By roosting in a tree, IVCs boost their flying capacity, although they are not good at flying. In the absence or inaccessibility of a perch, for example, commercial chickens show the sign of frustration and/or enhanced exploration, which shows the importance of a suitable roosting site to maintain the welfare of domestic fowls (Olsson and Keeling 2000).

However, brooding hens may face difficulties roost in a tree. To develop the roosting skill of chicks, a training rooster can be placed inside a night enclosure when the chicks are 3 weeks old. For example, a bamboo ladder is placed around the roosting tree in Nicaragua (de Vries 2000) to assist roosting. At about 6 weeks of age, the chicks can roost in lower branches of trees (McBride et al. 1969). Interestingly, the fledglings can comfortably roost in trees at 3 months of age (Cockell 1924). While roosting in trees, IVCs feel comfortable because it is easier for them to grasp the round branch of trees and they have developed this behavior in the course of their breeding and management history. A smaller weight of IVCs enables them to fly up and roost in trees. Unlike IVCs, junglefowl change their regular roosting site following disturbance (Collias and Collias 1967), however, the 
disturbance is limited in IVCs that are roosting inside the farmers' residence.

Roosting in trees enables IVCs to develop resilience against weather change. The glossy feather of IVCs enables them to drip off the heavy shower of tropical rain. Moreover, they may to some extent suffer from bad weather (Aline 2015), however, IVCs are found to be resilient to bad weather (Nhleko et al. 2003). Ectoparasites that might be found in barks or holes of trees particularly at a lower height may infest chickens (Canale et al. 2000), however, some farmers spread fresh wood ash on tree bark to get rid of ectoparasites and insects.

\section{Marginal benefits of roosting in trees}

Roosting trees provide nutritious fruits and small leaves to chickens (Hofner and Folsch 2001). In turn, the IVCs nourish the roosting trees with their droppings and they can graze on undergrowing weeds that otherwise compete with the roosting trees for nutrients. The use of fruit trees as overnight roosting sites at the same time produces fruit for human consumption. In the hot tropics, roosting in trees relieves chickens from the heatwave of the hot ground (Thaxton 2003). Unlike perch, roosting trees provide multi-layered vertical spaces that can accommodate several birds and/or entertains pecking order. The use of roosting trees can be also added an extra layer of importance to the agroforestry system and the presence of roosting trees improves the quality of the micro-environment in the farmers' backyard. From the economic feasibility perspective, roosting in trees eliminates the cost of construction and maintenance of night enclosures and the cost associated with cleaning of night enclosures and acquisition and replacement of bedding materials. Roosting in trees is an ancient and unique practice and it carries the legacy of ancient chicken keepers, which virtually deserves conservation and extensive studies.

\section{Conclusions}

The well-established practice of roosting in trees should have to be treated with caution while intervening with the night enclosure system. There is no need for disregarding the traditional practice while the current state of knowledge on the rationale behind roosting in trees is limited. However, sustainability, economic feasibility, and the associated welfare issues need to be thoroughly assessed to make an informed decision on its comparative advantage. Meanwhile, the instinct of IVCs ought to be revisited while recommending conventional night enclosures. This piece of work elicits research questions to conduct in-depth studies on the feasibility of roosting in trees and its socio-biology relevance.
Acknowledgements

Not applicable.

Authors' contributions

The author read and approved the final manuscript.

Funding

This work did not receive any specific funding.

Availability of data and materials

Not applicable.

\section{Declarations}

Ethics approval and consent to participate

Not applicable.

Consent for publication

Not applicable.

Competing interests

The author declares no competing interests.

Received: 17 March 2021 Accepted: 14 May 2021

Published online: 22 May 2021

\section{References}

Ahlers C, Alders RG, Bagnol B, Cambaza AB, Harun M, Mgomezulu R, Msami H, Pym B, Wegener P, Wethli E, Young M. Improving village chicken production: a manual for field workers and trainers. ACIAR Monograph No. 139. Canberra: Australian Centre for International Agricultural Research; 2009.

Aline K. Management systems and location effects on growth and carcass traits of Kuroiler and local chickens. MSc Thesis, Makerere University, Uganda. 2015.

Asem-Bansah CK, Sakyi-Dawson O, Ackah-Nyamike EE, Colecraft EK, Marquis GS. Enhancing backyard poultry enterprise performance in the Techiman area: a value chain analysis. Afr J Food Agric Nutr Dev. 2012;12(1):5759-75.

Bibi S, Noreen S, Rehman A, Mehmood S, Shah M. Morphological characteristics of native chicken of village Chhajjian, Haripur Pakistan. Poult Sci. 2021;100(3):100843

Canale DM, Cecere MC, Chuit R, Guè Rtler RE. Peridomestic distribution of Triatoma garciabesi and Triatoma guasayana in north-west Argentina. Med Vet Entomol. 2000;14:383-90.

Cockell FH. Cost of rearing pullets to six months of age. Oregon Agricultural College. Extension Service. Extension Bulletin 379, Corvallis, Oregon. 1924.

Collias NE, Collias EC. A field study of the red jungle fowl in north-central India. Condor. 1967:69(4):360-86.

Desta TT. Phenotypic characteristic of junglefowl and chicken. World's Poult Sci J. 2019;75(1):69-82.

Desta TT. Indigenous village chicken production: a tool for poverty alleviation, the empowerment of women, and rural development. Trop Anim Health Prod. 2021:53(1):1-16.

de Vries H. Observations on management and production of local chickens kept in Muy Muy, Nicaragua. Data presented on a poster on the World Poultry Congress of Montreal, Canada, 2000.

Dryden J. Incubating and Brooding Chickens. Oregon Agricultural College Bulletin, Department of College Extension, Bulletin- No. 6. Poultry Husbandry, Reading-Course Lesson 5, Corvallis, Oregon. 1910.

El-Yuguda AD, Ngulde IS, Abubakar MB, Baba SS. Village chicken health, management and production indices in selected villages of Borno State. Nigeria Fam Poult. 2007:17(1 \& 2):41-8.

FAO. Poultry Sector Mozambique. FAO Animal Production and Health Livestock Country Reviews. No. 5. Rome. 2013.

Getu A, Birhan M. Chicken production systems, performance and associated constraints in North Gondar Zone. Ethiopia J Fish Livest Prod. 2014:2:115. 
Hassan DI, Ogah DM, Yusuf ND, Musa-Azara IS, Ari MM, Alaga AA. Village chicken flock ownership, management and constraints in Keana, Nasarawa state. Nigeria Egypt Poult Sci. 2012;32(IV):809-17.

Henning J, Pym R, Hla T, Kyaw N, Meers J. Village chicken production in Myanmar-purpose, magnitude and major constraints. World's Poult Sci J. 2007;63:308-22

Hinkle NC, Corrigan RM. External parasites and poultry pests. Dis Poult. 2020:1135-1156.

Hofner M, Folsch DW. Optimizing free-range systems for laying hens. In: Oester $\mathrm{H}$, Wyss $\mathrm{C}$, editors. Proceedings of the 6th European symposium on poultry welfare, Zollikofen, Switzerland, 2001. p. 38-40.

Huchzermeyer FW. Why is velogenic Newcastle disease endemic in some countries and not in others? Zimb Vet J. 1993:24:111-3.

Leahy C. The Birdwatcher's Companion. New York: Gramercy Books; 1982.

McBride G, Parer IP, Foenander F. The social organisation and behaviour of the feral domestic fowl. Anim Behav Monogr. 1969;2:127-81.

Moore WJ. Managing the laying flock. Issued by The Agricultural Extension Service, The Texas A. \& M. College System and The United States Department of Agriculture, n.d.

Morêki JC. Village Poultry and Poverty Alleviation. In: Community-Based Management of Animal Genetic Resources. Proceedings of the workshop held in Mbabane, Swaziland, 7 to 11 May 2001. Rome: Food and Agriculture Organization of The United Nations; 2003. p. 155-64.

Nhleko MJ, Slippers SC, Lubout PC, Nsahlai IV. Characterisation of the traditional poultry production in the rural agricultural system of KwazuluNatal. A paper presented at the 1st National Workshop on Indigenous Poultry Development, Nature and Development Group of Africa. 2003.
NSPD (Network for Smallholder Poultry Development). Keeping Village Poultry. A technical manual on small-scale poultry production. Copenhagen: NSPD; 2007.

Olsson IAS, Keeling $L$ J. Night-time roosting in laying hens and the effect of thwarting access to perches. Appl Anim Behav Sci. 2000;68:243-56.

Spradbrow PB. The epidemiology of Newcastle disease in village chickens. In: of an International Workshop. ACIAR No 103, Maputo, Mozambique, 2001. p. 53-5.

Thaxton JP. Stress and the welfare of laying hens. In: Perry GC, editor. Welfare of the laying hen poultry science symposium series, vol. 27. Proceedings of the world's poultry science association meeting held in Bristol, England. Wallingford: CABI Publishing, CABI International; 2003. p. 81-95.

Thiel D, Unger C, Kéry M, Jenni L. Selection of night roosts in winter by capercaillie Tetrao urogallus in Central Europe. Wildl Biol. 2007;13(1):73-86.

Vijh RK, Chatterjee RN, Vij PK, Tantia MS, Ahlawat SPS. Chicken breeds of IndiaNicobari. Leaflet 36. Karnal: National Bureau of Animal Genetic Resources; 2006

Wood-Gush DG, Duncan IJ. Some behavioural observations on domestic fowl in the wild. Appl Anim Ethol. 1976;2(3):255-60.

\section{Publisher's Note}

Springer Nature remains neutral with regard to jurisdictional claims in published maps and institutional affiliations.
Ready to submit your research? Choose BMC and benefit from:

- fast, convenient online submission

- thorough peer review by experienced researchers in your field

- rapid publication on acceptance

- support for research data, including large and complex data types

- gold Open Access which fosters wider collaboration and increased citations

- maximum visibility for your research: over $100 \mathrm{M}$ website views per year

At BMC, research is always in progress.

Learn more biomedcentral.com/submissions 